\title{
A CONTRIBUTION
}

TO THE

\section{NATURAL HISTORY OF PULMONARY CONSUMP'TION,}

CONSISTING OF AN ANALYSIS OF

ONE HUNDRED MALE CASES OF HAEMOP'TYSIS.

BY

HORACE DOBELL, M.D.,

SENIOR PHYSICIAN TO THE ROYAL HOSPITAL FOR DISEASES OF THE CHEST.

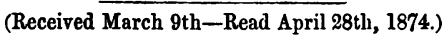

THe primary object of this investigation has been to assist, by clinical observation, in settling the important question of the true position of hæmoptysis in the natural history of pulmonary consumption.

With this intention, the cases discussed in this paper were recorded upon a plan of inquiry so designed that it should, as far as possible, avoid the chance of prejudice from preconceived opinions and impressions, and include all the facts essential to the investigation in a tabular form.

With so ample a field for observation as.is afforded by the Royal Hospital for Diseases of the Chest, it would have been easy to accumulate a much larger number of cases, if I could have entrusted the work to an assistant. But feeling 
that the whole value of the investigation depended upon my being able to guarantee that the histories of the cases had been sifted and verified in the most rigorous manner, there was no alternative but to do all the work myself.

I regret that this necessity and the small amount of leisure at my command have obliged me to limit my record to 100 cases of hæmoptysis-a number too small to form more than "a contribution" to the statistics of the subject. I trust, however, that if the plan which I have adopted should be thought worthy of imitation, other observers, with more time at their disposal, will follow it up, and thus accumulate a sufficiently large mass of comparable facts, arranged on a uniform plan, to form a safe basis for final conclusions.

Having decided upon the plan for the tabulated records, it was next of the highest importance that the cases should be representative of the ordinary average varieties of hæmoptysis, absolutely free from any selection dictated by special views, and yet, that they should be selected, in the sense of each containing the elements essential to the leading points of the inquiry. To obtain these ends the following precautions were rigorously carried out.

All cases occuring in my practice at the Royal Hospital were asked if they had ever expectorated any blood. If the answer was "Yes," the case was sifted in the following manner :

1. All cases were rejected in which the blood had never been seen in any other form than streaks in the phlegm.

2. All cases were rejected unless the heaviest weight before the occurrence of hæmoptysis could be stated from actual weighing, and reasonable evidence given as to whether this had been the average weight up to the time of first hæmoptysis.

3. All cases were rejected who could not stand a searching cross-examination as to the time at which the first loss of weight, if any, had begun.

It is in this inquiry that the greatest patience and caution are required; for the first answers given by patients to direct questions on the subject of loss of flesh and loss of weight 
are almost invariably wrong and of the most misleading description. Seeing the great difficulty there is in getting at the truth in this matter, one canrot help the conviction that many delusive conclusions may have been arrived at based upon statements elicited without a sufficient knowledge of the necessity for caution on this point.

It will at once be recognised how very large a number of cases of hæmoptysis must have been rejected on these three counts.

4. I soon found that it was necessary to reject all females from the reports, and for the following reasons: (a) Their weights before admission could not be relied upon, the majority had never been weighed till they came to the hospital, and even if they had been weighed, the differences of clothing were found to present more unavoidable sources of fallacy than in men. (b) Pregnancy, childbearing, and lactation were constant elements of fallacy as to weight. (c) Hæmoptysis was found to be complicated with climacteric and other derangements of the menstrual functions to an extent seriously damaging its clinical meaning with relation to consumption. (d) In pushing a close inquiry into the history of a case, it was much more difficult to obtain a connected and reliable account of facts from the hospital class of women than from men of the same class. This rejection of all females from my inquiry was a serious loss, diminishing the number of eligible cases by about one half.

5. All cases were rejected in which there was reasonable suspicion of cardiac complications.

6. All cases were rejected who could not give a fairly succinct account of the onset of cough.

7. All cases were rejected who could not give an approximative estimate of the quantity and character of the expectorated blood in the first and subsequent hæmoptysis.

8. And, finally, after the inquiry had been completed, all cases were rejected if it was found on comparing the principal statements that they were inconsistent with one another.

It will be seen that the elements of these rigorous rejec- 
tions are such that they do not give the cases a selected character in the sense of invalidating their claim to represent an unprejudiced average of cases of hæmoptysis occurring at a public hospital. They may, therefore, be considered to form a fairer basis for statistics than if no selection had been made,-having the great advantage that incomplete and unreliable reports are excluded.

It is evident that the labour of recording 100 cases was immensely enhanced by the above plan; but I think it will be felt that the value of the facts obtained has been proportionately increased.

If we allow for each case accepted one rejection on the 4th count (sex), two on the 3rd count (history of first loss of weight), two on the 2nd count (history of actual heaviest weight), and one between counts 6,7 , and 8 (and these numbers are below the truth), the 100 cases will be representative of an average succession of not less than 700 cases, in addition to the cases excluded under cardiac complications (count 5), and hæmoptysis in streaks only (count 1).

On examining the general table (Table 1$)^{1}$, it will be seen that each line in the horizontal direction represents a complete case. The primary object, as already stated, was to ascertain the true position of hæmoptysis in the etiology of consumption. But it was necessary to this end that a number of circumstances connected with each case should be recorded, which form a basis for a variety of other inquiries. It has been an especial object of my care, therefore, in arranging and analysing the records to place them in such a form that others can work from them just as well as myself. Indeed, it is chiefly with this view that I have wished to place the whole of the materials in the hands of the Society.

I regret that the work of collecting, tabulating, and analysing has occupied so much more time than I anticipated that it has left but little at my disposal for the purpose of reasoning and drawing conclusions from the results; and I must offer this as my apology to the Society

1 The table has been found too large and intricate for publication (see Abridged Summary, pp. 266-270). 
for presenting a paper which must, I fear, be tedious and uninteresting to hear, while the subjects which it offers for discussion are too numerous to be brought within the compass of a Society's meeting.

The following is an abridged summary of the most important facts contained in Table $I$, to which $I$ have added seventeen supplementary tables, ${ }^{1}$ in which some of the principal groups of facts are analysed and compared. Many other tables may yet be constructed with advantage to elucidate the meaning of other groups of facts contained in Table I, but for these I have not yet been able to find the time. On some future occasion I hope to be able to present a statement, in which the results of this investigation are compared with those obtained by Drs. Williams, Walshe, Niemeyer, and others-a work which I have already commenced.

1 It has not been found practicable to publish these long and complicated tables. 


\section{Abridged Summary of Table I.}

\begin{tabular}{c|c} 
Columns & $\begin{array}{c}\text { The Table consists of an analysis of } 100 \text { cases of hæmo- } \\
\text { ptysis in males, in all of which some disease existed in } \\
\text { the upper lobes of the lungs at the time the note of the } \\
\text { case was taken. }\end{array}$
\end{tabular}

The average age was 33.37 years.

The condition of the lungs is classified in Table II (not published).

The general symptoms were moderate in 43 per cent., severe in 41 per cent, extreme in 11 per cent.

The average present weight of each patient was 122.97 pounds.

The average heaviest weight (ever attained by each patient) was 142.62 pounds.

The average present weight was therefore less than average heaviest weight by $19 \cdot 65$ pounds.

In not one case was the present weight greater than the heaviest previous weight.

The present weight was less than the former weight in every case.

The heaviest weight had been entirely regained in 2 per cent.; but in each of these cases present weight was less than previous heaviest weight (see these cases, Cases 43, 97, with commentaries). ${ }^{1}$

The average time elapsed since loss of weight began was $950 \cdot 17$ days.

A cause for the loss of weight was assigned by the patient in 70 per cent.

1 It has not been found practicable to publish the cases. 
Abridged Summary of Table I-continued.

Columns 21 to 35.

Previons to admission of patient loss of weight had been treated with cod oil in 28 per cent., with pancreatic emulsion in 1 per cent., with oil and emulsion in $15 \mathrm{per}$ cent., with a voyage in 1 per cent. No treatment had been adopted in 55 per cent.

The average time elapsed since first cough began was 1464:4 days.

A cause of first cough was assigned in 50 per cent.

First cough began before first loss of weight in 69 per cent. " " after first loss of weight in 31 per cent. " " before first hæmoptysis in 87 per cent. " " after first hæmoptysis in 2 per cent. (These two cases, with commentaries, were given in detail, Cases, G. H., 26 ; R. W., 62. (Case 26, not published ; Case 62, published, $p$. 277.)

" $\quad$ At the same time as first hæmoptysis, i. e., was accompanied by it, in 12 per cent. (These twelve cases were further analysed in Table III, not published.)

The average time elapsed since present cough began (cough presont at time of admission) was 915.45 days.

The average time elapsed between the beginning of first cough and the beginning of present cough was 548.95 dajs.

A cause for present cough was assigned in 50 per cent.

Present cough began before loss of weight in 63 per cent.

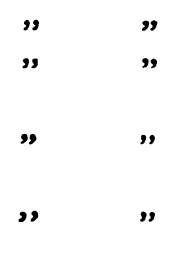
after loss of weight in 37 per cent. before first hæmoptysis in 77 per cent. after first hæmoptysis in 10 per cent.

at the same time as first hæmoptysis in 13 per cent. 


\section{Abridged Summary of Table I-continued.}

Columns 36 to 47.
The average time elapsed since the occurrence of first hæmoptysis in each case was 633.05 days. Comparing this with column 19, which shows that the average time elapsed since first loss of weight began was 950.17 days, it is seen that first loss of weight began on an average $317 \cdot 12$ days before first hæmoptysis.

But this general average is corrected in Tables IV, V, and VI (not published).

Table IV shows that in 8 cases loss of weight began on an average 853 days after first hæmoptysis.

Table $\nabla$ shows that in 82 cases loss of weight began on an average 469.78 days before first hæmoptysis.

Table VI shows that in 10 cases first loss of weight and first hrmoptysis were coetaneous.

The blood expectorated in first hæmoptysis was mixed in the sputa (flesh coloured) in 12 per cent.

Black or dark blood in 1 per cent. (In this case over ऊx in quantity, followed by smaller quantities on several occasions, produced by lifting.)

Florid blood in 76 per cent.

In small clots in 15 per cent.

In streaks in 9 per cent. (In each of these cases blood was subsequently expectorated in some other form.)

The quantity of blood expectorated in first hæmoptysis was under 3 ss in twenty-four hours in 11 per cent.

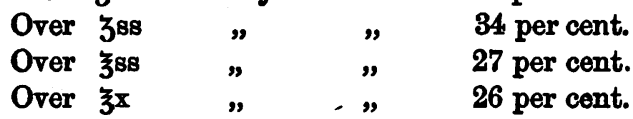

A cause for first hæmoptysis was assigned in 89 per cent.

First hæmoptysis occurred before the period of heaviest weight in 2 per cent. (Analyses of these cases were given, but are not published.)

After the period of heaviest weight in 87 per cent. 


\section{Abridged Summary of Table I-continued.}

Columns 48 to 67 .

First hæmoptysis occurred before first loss of weight in 8 per cent. (Analysed in Table IV, not published.)

$" \quad$ " after first loss of weight in 82 per cent. (Analysed in Table $\nabla$, not published.)

$" \quad " \quad$ at the same time as first loss of weight in 10 per cent. (Analysed in Table VI, not pub. lished.)

Hæmoptysis had recurred in 78 per cent.

First loss of weight occurred at the time of recurrence of hæmoptysis in 2 per cent. (These two cases were given in detail with commentaries, not published.)

Columns 52 to 65 give particulars of the quantity and quality and other details of recurrent hæmoptysis.

The family history shows that

Father only was consumptive in 9 per cent.

Mother " " 3 per cent.

Both father and mother were consumptive in 5 per cent.

Either one or both parents were consumptive in 17 per cent.

One brother (and no sister) was consumptive in 14 per cent.

One sister (and no brother) was consumptive in 7 per cent.

Three sisters (and no brother) were consumptive in 1 per cent.

One brother and one sister were consumptive in 4 per cent.

Two brothers and one sister were consumptive in 1 per cent. 


\section{Abridged Summary of Table I-continued.}

Column: 68 to 73

Either brothers and sisters, or brothers or sisters, were consumptive in 26 per cent.

One paternal uncle or aunt (no maternal) consump. tive in 3 per cent.

One maternal uncle or aunt (no paternal) consumptive in 0 per cent.

One paternal and one maternal uncle or aunt con. sumptive in 1 per cent.

Either paternal or maternal or both paternal and maternal uncles and aunts were consumptive in 4 per cent.

In no case more than one uncle or one aunt on the same side consumptive.

One paternal (and no maternal) first cousin consumptive in 1 per cent. (In no case more than one.)

One maternal (and no paternal) first cousin consumptive in 1 per cent. (In no case more than one.)

Both paternal and maternal first cousins consump. tive in 0 per cent.

Only one relative was consumptive in 19 per cent.

Only two

Only three

Only four

$"$

"

" 7 per cent.

"
7 per cent.

1 per cent.

In only one case were more than four relatives consumptive, this was Case 5 , in which mother, one brother, three sisters, one first cousin (paternal), were consumptive.

It is seen, therefore, that in the 100 cases there were 59 consumptive relatives, or, including the patients them. selves, 159 consumptive individuals.

With reference to the important question of the true position of hæmoptysis in the natural history of pulmonary consumption, it will be observed that the 100 gases tabulated 
in Table $I$ arrange themselves into three great clinical groups, characterised by the relation in point of time between the first hæmoptysis and the first loss of weight.

And again into three other groups, characterised by the relation in point of time between the onset of first cough and the occurrence of first hæmoptysis.

And again into two groups, characterised by the relation in point of time between the onset of first cough and the onset of first loss of weight.

First hæmoptysis occurred before first loss of weight in 8 cases (8 per cent.). (Table IV, not published.)

- At the same time as first loss of weight in 10 cases (10 per cent.). (Table VI, not published.)

- After first loss of weight in 82 cases ( 82 per cent.). (Table V, not published.)

First cough occurred before first hæmoptysis in 87 cases (87 per cent.).

- At the same time as first hæmoptysis in 12 cases (12 per cent.). (Table III, not published.)

- After first hæmoptysis in 2 cases ( 2 per cent.). (See abridged summary of Table $I$, p. 267.)

First cough occurred before first loss of weight in 69 cases (69 per cent.).

- After first loss of weight in 81 cases ( 31 per cent.).

I have taken loss of weight as the most palpable sign of constitutional deoline, and Column 16, Table I, shows that in every one of the 100 cases the patient weighed less than he had done at a previous period of his life ; and a comparison of Columns 14 and 15, Table I, shows that the average loss of weight per patient was $19 \cdot 65$ pounds. The rate at which this loss had occurred in the different groups of cases is shown in Table VIII (Table not published, abstract given below'), and

1 In 82 cases in which loss of weight began before first hæmoptysis-Rate about 7 pounds per 365 days.

In 10 cases in which loss of weight began at same time as first hæmoptysis -Rate about 8 pounds per 365 days.

In 8 cases in which loss of weight began after first hæmoptysis-Rate about 11 pounds per 365 days. 
in Table IX (not published) I have shown the total loss of weight and the rate at which loss of weight had occurred at the different stages of lung disease.

Column 18, Table 1 (not published), shows that in only two cases out of the 100 had the previous heaviest weight been entirely regained at any time since the first onset of disease; and in these two the recovery of weight was altogether exceptional in its circumstances and meaning, as shown in the commentaries on the cases (not published).

Column 28, Table I, shows that in 12 cases cough began at the same time as first hæmoptysis, and I have constructed a special Table for this group of cases in which the leading facts of each can be seen at a glance (Table III, not published).

It is a striking fact that 82 of the 100 patients had lost weight before the occurrence of the first hamoptysis-the average time during which this loss had taken place previous to the hæmorrhage being no less than 469.7 days. It is then self-evident that in these 82 cases some diseased condition existed before the occurrence of hæmorrhage, and that, therefore, we have no reason for seeking a cause in the hæmoptysis.

Our special interest is, therefore, concentrated upon the 18 cases forming the two smaller groups arranged in Tables IV and VI (not published).

In Table IV it is shown that first hæmoptysis preceded first loss of weight by 853 days on an average in 8 cases.

In Table VI first hæmoptysis and first loss of weight were coetaneous in 10 cases.

In either of these groups, therefore, it is clearly possible to urge that the hæmoptysis was the cause of the constitutional decline, and of all the local disease accompanying it.

To each of these 18 cases, therefore, I have devoted a special commentary, with a view to clearing up as far as possible the position of the hæmoptysis as a cause of disease ; and these commentaries may be examined immediately. ${ }^{1}$

1 It has only been practicable to publish Cases 62, 17, 58, 42, 93, and their commentaries. 
First, however, it is necessary to point out that one clinical fact, in addition to hæmoptysis and loss of weight, at once assumes a right to prominence in discussing these cases. I mean the onset of the first cough $h^{1}$ and its relation in point of time to the occurrence of first hæmoptysis. I have therefore given it a special place in Tables IV and VI. For as cough must be taken to indicate some defective condition of the respiratory organs, if cough preceded first hæmoptysis by any appreciable period of time, it throws at once a grave doubt upon the claim of the hæmorrhage to be regarded as the first cause of the lung disease.

Now we have seen by Table I that out of the 100 cases first cough preceded first hæmoptysis in 87, and began after the first hæmoptysis in only 2.

And turning to the 18 cases now more particularly under consideration, it is seen, by Table IV, that first cough preceded first hæmoptysis by 924 days on an average in 7 out of the 8 cases, and thus indicated that some kind of mischief was going on in the respiratory tract before bleeding occurred. In the one case out of the 8 (Case 62) in which the cough began 84, days after the first hæmoptysis the circumstances were peculiar, and are fully discussed in the commentary to the case (see p. 278).

In Table VI it is seen that in 6 out of the 10 cases cough preceded first hæmoptysis by 1600 days on an average, the minimum being 197 days. In the other four cases the cough, hæmoptysis, and loss of weight began at the same time. These were Cases 17 (p. 279), 42 (p. 282), 58 (p. 284). In each of these cases it will be seen that there is room for the conclusion that the lung disease proceeded from the hæmorrhage, although in neither of them is this conclusion inevitable. And the same may be said of Case 15 (not published), Table IV; in which first hæmoptysis preceded loss of weight. The commentaries on these cases therefore claim

1 In recording "first cough" care was taken only to take note under that head when some connection could be reasonably traced between the cough and the illness connected with first hæmoptysis. 
our special consideration. But in Case 93 (p. 285) our interest culminates, for in it there appears to be no room for any more rational conclusion than that the lung disease was produced by the damage done by the hæmorrhage (see p. 275, par. $d$ ).

Among the many subjects of interest contained in Table I, for which I have not time in this paper, I may mention one intimately connected with the cases herein discussed. I mean the question, whether the results of pulmonary hæmorrhage bear any relation, in respect to tissue damage, to the quantity of blood expectorated in hæmoptysis. The materials for a separate table representing the facts relating to this question are to be found in Table $I$; and at some future day I hope to deal with them. In this place I will only say that $I$ am disposed to think that it is of more importance whether the hæmorrhage has taken place into the respiratory tubes, or into the pulmonary tissues, than whether it has been profuse or slight. Analogy lends weight to this opinion, as seen in cerebral hæmorrhage, and other instances of bleeding into the tissues, and into the passages of internal parts.

It will be observed that throughout this paper, and in the commentaries on the cases, I have studiously avoided entering upon questions of pathological histology and the use of debateable terms, my objest being to keep as strictly as possible to a simple analysis of the clinical facts presented by the cases produced.

In conoluding, however, I may just venture to enumerate what appear to me to be some of the principal heads under which hæmoptysis may be arranged in the natural history of pulmonary consumption, as justified by clinical observa. tion.

As a symptom it may be thus elassified-

1. In a large number of cases it is simply the result of congestion and disintegration of a highly vascular organ, in the course of a disease of constitutional origin. 
2. In a large number of cases it is simply the result of congestion and disintegration of a highly vascular organ in the course of diseases of local origin.

3. In a certain number of cases it is simply the result of accidents temporarily overdistending the vaseular system of the lungs, and leading to their rupture; in the same way as similar overdistension leads to rupture of vessels in other parts of the body. 1

4. In a certain number of cases it is the result of the bursting of small aneurisms in the lungs formed in the course of lung disease.

As a cause of lung disease and constitutional decline-

I am disposed to place it only as one item, and that a very occasional one, in a large and important group, embracing all foreign substances which find their way into the perivascular and perialveolar tissue of the lungs, and by their irritation there, set up lymphatic (adenoid) and connective tissue cell-proliferation and its consequences.

Of this important group the following are some of the principal constituents :

$a$. The dust of flint, coal, iron, and other substances inhaled by workers in different dusty trades.

$b$. The products of inflammatory destruction of tissue.

c. The products of catarrhal affections.

$d$. The débris of blood, and of tissues disintegrated by the extravasation of blood (see Case 93, referred to, p. 274).

$e$. Albuminoid tissue disintegrated by peroxidation, in true tuberculosis. ${ }^{2}$

1 Whether such overdistension is competent to cause rupture of vessels, the walls of which are not previously diseased, is a very wide question, which must be argued with reference to the whole vascular system before it is specialised within the narrower area of the pulmonary circulation. Is it necessary to assume that a vessel was diseased because it burst under exceptional distension?

2 In my opinion the disintegrated albuminoid tissue is the irritant which 
Lastly, hæmoptysis may possibly become a cause of lung disease by accumulation of blood débris in the alveoli (see Case 93, p. 285).

sets up that hyperplasia of adenoid tissue and its results, so well described by Portal, Virchow, Sanderson, and Rindfleisch. But whereas they place this hyperplasia first among the pathological changes of tuberculosis, I give precedence to the peroxidation and disintegration of albuminoid tissue, of which the hyperplastic changes are but the effects, the order of events being, according to my view-

a. Deficiency of fat in the blood.

b. Peroxidation of albuminoid tissue.

c. The production of disintegrated albuminoid tissue, the result of peroxidation.

d. Hyperplasia of adenoid tissue, the result of irritation of the absorbent system engaged in removing the disintegrated tissue.

Whether the disintegrated albuminoid tissue, or the resulting diseased adenoid tissue shall be called "tubercle" is of little consequence, so that the distinction in the order of events is borne in mind. 
From the analysis of 8 cases, in which first hamoptysis occurred before first loss of weight. (Table IV, not published.) $)^{1}$

\begin{tabular}{|c|c|}
\hline $\begin{array}{l}\text { Case } 62 . \\
\text { R. W-. }\end{array}$ & $\begin{array}{l}\text { Male. } \\
\text { Age } 27 . \\
\text { Right lung, softening }\} \text { upper parts. } \\
\text { Left lung, softening } \\
\text { General symptoms extreme. } \\
\text { Present weight, } 111 \text { pounds. } \\
\text { Heaviest weight, } 131 \text { pounds. } \\
\text { Present weight less than heaviest weight by } 20 \text { pounds. } \\
\text { Time elapsed since first loss of weight, } 252 \text { days. } 28 \text { days } \\
\text { after first hæmoptysis. } \\
\text { Cause of first loss of weight assigned, nil. } \\
\text { Time elapsed since first cough began, } 196 \text { days. } 84 \text { days } \\
\text { after first hæmoptysis. } \\
\text { First cough began after first loss of weight, } 56 \text { days. } \\
\quad \text { " after first bæmoptysis, } 84 \text { days. } \\
\text { Present cough began at the same time as first cough (it } \\
\text { had never ceased). } \\
\text { Time elapsed since first hæmoptysis, } 280 \text { days. } 28 \text { days } \\
\text { before first loss of weight. } \\
\text { The blood of first hæmoptysis was florid. } \\
\text { The blood of first hæmoptysis was in quantity over } 3 \times \text { in } \\
24 \text { hours. } \\
\text { The cause of first hæmoptysis assigned was “ dancing, and } \\
\text { drinking iced ale." } \\
\text { First hæmoptysis occurred before first loss of weight by } \\
28 \text { days. } \\
\text { Hæmoptysis did not recur. } \\
\text { The family history was free from consumption. }\end{array}$ \\
\hline
\end{tabular}

1 This is one of two cases in which first cough began after first hæmoptysis (pp. 267, 273). 
Commentary. - This is a typical case of consumption proceeding prim $\hat{a}$ facie entirely from hæmoptysis. Nothing could be extracted by the most careful inquiry to account for the hæmorrhage, except the cause assigned by the patient, viz., that " while at his full weight and in usual health he overheated himself with dancing, and then drank some iced ale, and immediately broke a blood-vessel in his chest." No recurrence of hæmorrhage had taken place. Loss of weight began about a month after the accident, and twenty pounds had been lost in 252 days. No cough set in till 84 days after the accident and 56 days after the loss of weight, but since it began it had never ceased. This is a remarkable circumstance, for if the decline in health, indicated by loss of weight, were due to local disease set up by the hamorrhage, it is very improbable that it should not have excited the ordinary symptom of lung disease or irritation, viz., cough.

When we regard these facts in relation with the condition of the lungs on admission, i. e., softening of both upper lobes, it becomes still more remarkable that no cough should have been excited by the hæmorrhage, if it be supposed that the structure of both lungs was so much damaged by the effusion of blood as to lead to all that followed. My opinion is that these circumstances throw the greatest doubt upon such a supposition, and I am led to put aside the prima facie conclusion that the whole case started from the hæmorrhage, and to conclude, instead, that the following is a much more probable solution:-That at the time the accident occurred the patient was not in such unquestionable health as he imagined; that his habits of dancing, drinking, and late hours were telling upon his constitution; that his subsequent decline was imminent at the time of the accidental hæmorrhage; that the hæmorrhage brought on by the temporary overheating and excitement, instead of causing disease of the lungs, protected them ; that the relief to the vascular system, combined with the rest and ease enforced by the alarm caused by the hæmorrhage, actually postponed those changes in the lung which, otherwise, might have appeared much sooner than they did; 
and that thus it is that we have a history of twenty-eight days in which no obvious change took place in the healththen constitutional decline and loss of flesh for fifty-six days, before sufficient irritation had occurred in the lungs to cause a cough. If then we put aside the hæmorrhage, as accidental, we see an ordinary case of consumption in which the events follow the usual order :

1. Damaged constitutional health (by fast living?).

2. Decline of weight and strength.

3. Lung irritation and cough.

4. Advancing lung disease and constitutional decline.

From the analysis of 10 cases, in which first hamoptysis and first loss of weight occurred at the same time. ('Table VI, not published.)

\section{Case 17. Male.}

A. G-. Age 31 .

$\left.\begin{array}{l}\text { Right lung normal } \\ \text { Left lung consolidated }\end{array}\right\}$ upper parts.

General symptoms moderate.

Present weight, 116 pounds.

Heaviest weight, 128 pounds.

Present weight less than former weight by 12 pounds.

Time elapsed since first loss of weight, 1460 days. Same time as first hæmoptysis.

Cause of first loss of weight assigned, hæmoptysis.

Loss of weight was not treated with either oil or emulsion.

Time elapsed since first cough began, 1460 days. It was accompanied by first hæmoptysis.

Cause of first cough assigned, nil.

First cough began before (just before) loss of weight. 
First cough began before, or at the same time as, first hæmoptysis.

Present cough began at the same time as first cough.

Time elapsed since first hæmoptysis, 1460 days; 1458 days before last hæmoptysis; 1108 days before first profuse hæmoptysis.

The blood of first hæmoptysis was florid.

The quantity of blood in first hæmoptysis was over $\xi$ ss in 24 hours.

Cause of first hæmoptysis assigned, nil.

First hæmoptysis occurred after heaviest weight. of weight.

at the same time as first loss

Hæmoptysis had recurred.

Time elapsed since last hæmoptysis, 2 days. 250 days after first profuse hæmoptysis; 1458 days after first hæmoptysis and first loss of weight.

The blood of last hæmoptysis was florid.

The quantity of blood in last hæmoptysis was over $\xi x$ in 24 hours.

Last hæmoptysis occurred after first loss of weight. 1458 days.

The father was consumptive.

The mother was consumptive.

One brother was consumptive.

Commentary.-Without assignable cause, hæmoptysis to the extent of $\xi s s$ in twenty-four hours occurred with cough 1460 days ago, and was immediately followed by loss of weight. Cough had continued ever since.

Eleven hundred and eight days after the first hæmorrhage a second and much more profuse bleeding occurred, and 230 days later a third and very profuse hæmoptysis took place. 
The only lung disease detected by physical examination was consolidation of the left upper lobe. The total loss of weight was twelve pounds in 1460 days. Consumption existed in both parents, and also in collaterals.

Seeing that the hæmorrhage occurred without any external cause, that 1460 days had elapsed since the first bleeding, and 252 days since the last, and that no other lung disease than consolidation existed, it would hardly be rational to consider the constitutional decline as due to this amount of disease, and therefore irrational to look upon the hæmorrhage as the cause of both the lung disease and loss of weight.

If the statement that no loss of weight had occurred up to the date of first hæmoptysis were correct, we are without palpable evidence of constitutional decline as a cause of lung disease prior to the hæmorrhage ; but the strong consumptive history in the family and the absence of external cause of hæmorrhage make it most probable that some hereditary defect existed. And as it appeared afterwards that the heaviest weight by weighing was taken two years before the first hæmoptysis, it is open to question whether he had not unconsciously lost weight in that time. He was weighed at the hospital at the time of the second hæmoptysis 250 days before he was weighed again (two days after the last bleeding); and on both of the occasions his weight was the same, but as he quickly gained four pounds under treatment, it showed that this weight had been a morbidly low one. Although, therefore, the case is obscure, there is no clear evidence that the hæmorrhage caused the lung disease. 
From the analysis of 10 cases, in which first homoptysis and first loss of weight occurred at the same time. (Table VI.)

\begin{tabular}{l|l}
\hline Rase 42. C-. & $\begin{array}{l}\text { Male. } \\
\text { Age 41. } \\
\text { Right lung consolidated and softening } \\
\text { Left lung normal } \\
\text { General symptoms moderate. } \\
\text { Present weight, } 143 \text { pounds. } \\
\text { Heaviest weight, } 159 \text { pounds. } \\
\text { Present weight less than heaviest weight by } 16 \text { pounds. } \\
\text { Time elapsed since first loss of weight, } 504 \text { days. Same } \\
\text { time as first hæmoptysis. } \\
\text { Canse of first loss of weight assigmed, hæmoptysis from } \\
\text { overlifting. }\end{array}$
\end{tabular}

Loss of weight had not been treated with either oil or emulsion.

Time elapsed since first cough began, 504 days. Same time as first hæmoptysis and first loss of weight.

Cause of first cough assigned, overlifting.

First cough began before loss of weight (just before). "Conghed and brought up blood, and then lost weight."

First cough began at the same time as first hæmoptysis.

Present cough began at the same time, and was assigned to the same cause as first cough.

Time elapsed since first hæmoptysis, 504 days.

The blood of first hæmoptysis was florid.

The quantity of blood in first hæmoptysis was over $\zeta$ ss in 24 hours.

The cause of first hæmoptysis assigned was cough from overlifting.

First hæmoptysis occurred at the same time as first loss of weight (i.e., loss of weight dated from coughing up the blond). 
Hæmoptysis had recurred.

Time elapsed since last hæmoptysis, 84 days. 420 days after first hæmoptysis.

The blood of last hæmoptysis was florid.

The quantity of blood in lust hæmoptysis was over 3 ss in 24 hours.

Family history free from consumption.

Commentary.-He was certain he was in usual health and usual weight (159 pounds) 504 days ago when he overlifted, coughed, and " broke a blood-vessel," and he had never been well since. In six weeks' treatment with oil and emulsion at the Royal Hospital he gained six pounds, but was still ten pounds below his average weight. Sixteen pounds weight had been lost in 504 days, commencing with first hæmoptysis and first cough. The cough is tabulated as beginning before hæmoptysis, because it was stated to have caused the hæmorrhage, but as no considerable interval occurred between the two-the cough coming on and hæmoptysis immediately following -it is quite possible that internal bleeding was the cause of the cough, instead of vice versâ.

The hæmoptysis was over 3 ss in twenty-four hours, and was assigned to cough produced by overlifting. Hæmoptysis had recurred; the last attack being over 3 ss in twenty-four hours 84, days ago.

There was no consumption in the family, and all illness apparently dated from the accident. The case is, therefore, fairly open to the opinion that the lung disease was set up by the hamorrhage, although that conclusion is not inevitable. 
From the analysis of 10 cases in which first hamoptysis and first loss of weight occurred at the same time. (Table VI.)

Case 58. Male.

A. B-. Age 22.

Right lung softening

Left lung excavated $\}$ upper parts.

General symptoms extreme.

Present weight, 99 pounds.

Heaviest weight, 118 pounds.

Present weight less than heaviest weight by 19 pounds.

Time elapsed since first loss of weight, 1095 days. (Same time as first hæmoptysis; same time as first cough; same time as present cough; 1088 days before last hæmoptysis.)

Cause of first loss of weight assigned, nil.

Loss of weight had not been treated with either oil or emulsion.

Time elapsed since first cough began, 1095 days.

Cause of first cough assigned, nil.

First cough began before first loss of weight (just before).

First cough began before first hæmoptysis (just before). (Cough was said to cause hæmoptysis, and therefore preceded it by a fraction of time.)

Present cough began at same time as first cough.

Time elapsed since first hæmoptysis, 1095 days.

The blood of first hæmoptysis was florid.

The quantity of blood in first hæmoptysis was over $\xi x$ in 24, hours.

Cause of first hæmoptysis assigned, cough.

First hæmoptysis occurred at the same time as first loss of weight. 
Hæmoptysis had recurred.

Time elapsed since last hæmoptysis, 7 days.

The blood of last hømoptysis was mixed with sputa (fleshcoloured sputa).

The quantity of blood in last hæmoptysis was under $3 \mathrm{ss}$.

Last hæmoptysis occurred after first loss of weight. 1088 days.

One brother was consumptive.

Commentary.-It was just before first hæmoptysis that he weighed the heaviest weight known (118 pounds), and he was certain no loss of weight had taken place up to that time, but he had been growing, and was only about 19 years old. One brother was consumptive, and as the break down (consisting in cough hæmoptysis and loss of weight without apparent cause) occurred just about the age of completion of growth, it is most probable that the symptoms were simply coëtaneous indications of the hereditary disease assuming an active stage. It is, however, open to discussion whether the hæmorrhage caused the subsequent changes in the lungs. The first hæmoptysis was over $3^{x}$ in twenty-four hours.

From the analysis of 10 cases in which first hamoptysis and first loss of weight occurred at the same time. (Table VI.)

Case 93. Male.

A. B-. Age 28.

Right lung consolidated
Left lung softening upper lobes.

General symptoms severe. 
Present weight, 112 pounds.

Heaviest weight, 149 pounds.

Present weight less than heaviest weight by 37 pounds.

Time elapsed since first loss of weight, 365 days. Just after, or at same time as, first hæmoptysis; same time as, or just after, first cough.

Cause of first loss of weight assigned, hæmoptysis.

Loss of weight had been treated with oil and emulsion.

Time elapsed since first cough began, 365 days.

Cause of first cough assigned, hæmoptysis. Cough accompanied and was said to cause hæmoptysis.

First cough began before, or at the same time as, first loss of weight.

First cough began before, or at the same time as, first hæmoptysis.

Present cough began at the same time, and was due to same cause as first cough.

Time elapsed since first hæmoptysis, 365 days.

The blood of first hæmoptysis was florid.

The quantity of blood in first hæmoptysis was over $\xi x$ in 24 hours.

The cause of first hæmoptysis assigned was overlifting a heavy weight.

First hæmoptysis occurred at the same time as first loss of weight.

Hæmoptysis had recurred.

Time elapsed since last hæmoptysis, 56 days. 309 days after first hæmoptysis.

The blood of last hæmoptysis was florid.

The quantity of last hæmoptysis was over 3 ss in 24 hours.

Last hæmoptysis occurred after first loss of weight, 309 days.

The family history was free from consumption. 
Commentary.-After six weeks' oil and emulsion he gained five pounds, making his weight 117 pounds $=32$ pounds less than heaviest weight. The heaviest weight known was three months before first hæmoptysis, and he declared there was no loss of weight or sign of illness up to the moment of his lifting a heavy weight, when he began to cough up blood profusely. The first hæmoptysis was said to be three pints of florid blood in twenty-four hours. From that time up to two months ago frequent smaller bleedings had occurred. Right lung very slightly consolidated; left, dull and chronically disintegrating, not very active.

In this case no consumption was known in the family, and everything appeared to date from an accidental strain in lifting a very heavy weight, which was immediately followed by extremely profuse hæmoptysis. An enormous loss of weight had taken place-thirty-seven pounds (a quarter of his total heaviest weight) in 365 days-in spite of treatment; and smaller bleedings had frequently occurred. One lung was consolidated, and the other slowly softening.

Under oil and emulsion he gained five pounds, but was still thirty-two pounds short of his normal weight.

This case approaches more nearly than any other out of the 100 here analysed to the description of Niemeyer's " galloping consumption, of which bronchial hæmorrhage is the immediate cause ;" but even here there is a history of $\mathbf{3 6 5}$ days, and the patient was still alive and beginning to gain flesh after his great loss, whereas Niemeyer speaks of such cases perishing in a few months.

This is the only case out of the 100 in which the most rational conclusion appears to be that the lung disease was caused by the hæmorrhage. (See pp. 273, 275, 276.) 